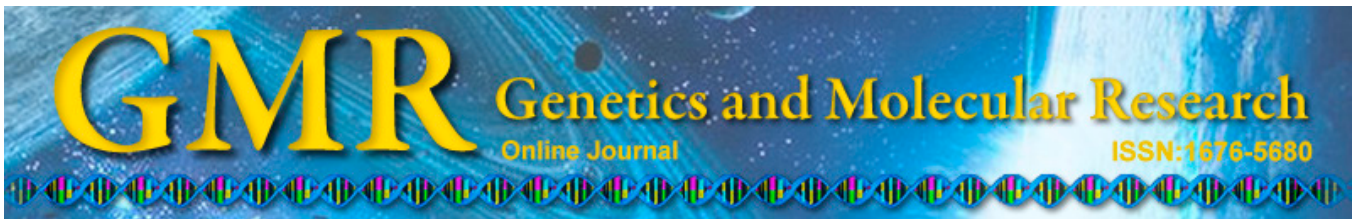

\title{
Roles of peripheral B1 cells in the individualized treatment of adult idiopathic thrombocytopenic purpura
}

\author{
H.-Q. Luo, Y.-G. Zhong, G.-Z. Zhou, J.-P. Fu and W.-Y. Feng \\ Department of Hematology, Shaoxing People's Hospital, Shaoxing, \\ Zhejiang Province, China \\ Corresponding author: H.-Q. Luo \\ E-mail: hongqiangluo@126.com
}

Genet. Mol. Res. 14 (1): 21-28 (2015)

Received September 7, 2014

Accepted December 20, 2014

Published January 15, 2015

DOI http://dx.doi.org/10.4238/2015.January.15.3

ABSTRACT. We aimed to explore the changes of peripheral B1 cells
before and after treatment of adult idiopathic thrombocytopenic purpura
(ITP) and to investigate the association of these changes with the disease
condition and prognosis. Ninety-seven ITP patients were divided into
the effective or ineffective groups, based on their response to hormone
therapy. Forty healthy volunteers were enrolled into the control group
$(\mathrm{HC})$. The percentages of CD $19^{+}$cells, B1 cells, and platelet-associated
immunoglobulin (PAIg) in peripheral blood from healthy volunteers
and ITP patients before and after treatment were evaluated, and blood
platelet (PLT) counts were determined. The percentages of CD19 $9^{+}$cells
$[(21 \pm 10.0) v s(11.2 \pm 7.1) \%]$, B1 cells $[(8.85 \pm 5.23) v s(2.2 \pm 1.3) \%]$,
and PAIg [ $(28 \pm 19) v s(11.7 \pm 8) \%]$ in whole blood from ITP patients
before treatment were significantly higher than those in whole blood
from healthy controls $(\mathrm{P}<0.05)$. Before treatment, the percentage of
B1 cells and PAIg in ITP patients was negatively correlated with the
PLT level $(\mathrm{r}=-0.89, \mathrm{P}<0.05$ and $\mathrm{r}=-0.814, \mathrm{P}<0.05$, respectively).
Further, the B1 cell percentage was positively associated with the PAIg
percentage in ITP patients before treatment. In the effective group, 
the B1 cell percentage was reduced sharply at 1 month after treatment $[(2.45 \pm 1.75) v s(8.74 \pm 5.04) \%, \mathrm{P}<0.05)]$, so as at 3 and 6 months. However, in the ineffective group, there was no difference in the B1 cell percentage before and after treatment $[(7.9 \pm 5.6) v s(8.76 \pm 5.26) \%]$. This obvious association of changes in peripheral B1 cells with disease condition and prognosis in ITP patients may be of certain clinical significance for guiding the individualized treatment of ITP.

Key words: Idiopathic thrombocytopenic purpura; B1 cells; Individualized treatment

\section{INTRODUCTION}

Primary idiopathic thrombocytopenic purpura (ITP) is an autoimmune disease. It was defined as a clinical syndrome early in the 16th century. However, in 1951, ITP was found to be closely related with other immunological disorders (Harrington et al., 1951), which present with excessive humoral and cellular immune-mediated destruction of platelets and quantitative and qualitative abnormalities of the megakaryocytes (Bussel et al., 2009; Yang et al., 2010; Godeau, 2013). Regarding the inadequate platelet production and the increased destruction of

platelets, preventing the excessive destruction of platelets and promoting thrombopoiesis have become indispensable strategies for the modern treatment of ITP (Rostami et al., 2008; Stasi et al., 2009; Arnold et al., 2009). It has been reported that the imbalances in B lymphocyte subpopulations and disorders of apoptosis are closely associated with the disease condition and prognosis of autoimmune diseases, such as systemic lupus erythematosus and rheumatoid arthritis (Arita et al., 2003). B1 cells are a population of $\mathrm{CD}^{+} \mathrm{B}$ cells that have been reported to be associated with the disease condition and prognosis of autoimmune diseases (Arita et al., 2003; Jackson et al., 2008). Recently, studies also showed that B1 cells have some relationship with the occurrence of ITP (Ruggeri et al., 2008; Rodeghiero et al., 2009; Chong, 2009; Provan et al., 2010; Johnsen, 2012). However, until now there has been no effective immunerelated indicator for evaluating the condition and prognosis of ITP (Spahr and Rodgers, 2008; Mueller et al., 2009; Salama et al., 2008, 2009; Mantadakis et al., 2010; Patel et al., 2012). In this study, we observed the level of peripheral B1 cells and evaluated the impact of ITP medication on this cell population to elucidate the pathogenesis of ITP and further clarify the roles of immune disorders in the pathogenesis of ITP. The relationship of B1 cells with the ITP condition and its prognosis were also explored to provide some immunological basis for the effective use of immunomodulatory means for stratification and individualized treatment.

\section{MATERIAL AND METHODS}

\section{Subjects}

Ninety-seven patients with ITP, who were hospitalized and received treatment in our hospital from December 2007 to December 2012, were enrolled in this study. Written and informed consent was obtained from each patient. ITP was diagnosed according to the "American Society of Hematology immune thrombocytopenia evidence-based practice guidelines 
(2011 Edition)" (Neunert et al., 2011). Patients with other immune-related diseases were excluded from the study. The subjects enrolled in this study included 34 male and 63 female patients with a mean age of 47.5 years (ranging from 17 to 67 years). Among the 97 patients with ITP in this study, 59 were sensitive to treatment with glucocorticosteroids (effective group), whereas 28 were insensitive to glucocorticosteroids (ineffective group). Forty healthy volunteers underwent a medical examination in our hospital, and those confirmed to be healthy were enrolled as the control group (HC), including 17 male and 23 female patients, with a mean age of 44.2 years (ranging from 19 to 65 years). This study was conducted in accordance with the declaration of Helsinki and with approval from the Ethics Committee of Shaoxing People's Hospital.

\section{Detection of $\mathrm{CD5}^{+}, \mathrm{CD}^{+} 9^{+}$, and $\mathrm{B} 1$ cells}

$\mathrm{CD}^{+}, \mathrm{CD} 19^{+}$, and B1 cells were detected using a direct immunofluorescence method. Briefly, 2 tubes (control tube and measuring tube) containing $100 \mu \mathrm{L}$ EDTA-anticoagulated blood sample and $20 \mu \mathrm{L}$ labeled monoclonal antibody, respectively, were used. CD5-FITC and CD19-PE monoclonal antibodies were added to the measuring tube, and CD19-PE and mouse anti-human IgG1 (Beckman-Coulter, Brea, CA, USA) $(20 \mu \mathrm{L}$ each) were added to the control tube, followed by thorough mixing. After incubation (dark, room temperature) for $15 \mathrm{~min}$, the sample was thoroughly mixed with $1 \mathrm{~mL}$ diluted hemolysin, followed by an incubation at room temperature for $8 \mathrm{~min}$. Following centrifugation at $1200 \mathrm{rpm}$ for $5 \mathrm{~min}$, the supernatant was removed, and $1 \mathrm{~mL}$ phosphate-buffered saline (PBS) was added. The samples were then mixed and centrifuged as above. After removing the supernatant, $300 \mu \mathrm{L}$ PBS was added, followed by detection. A 15-WV argon ion laser with an excitation wavelength of $488 \mathrm{~nm}$ was used as the laser source. Data were acquired and analyzed using the Cell Quest software. Forward and lateral scatter plots were used to differentiate distinct cell populations, and the lymphocyte populations were distinguished using gating technology. For each sample, 10,000 cells were detected, and the percentages of $\mathrm{CD}^{+}, \mathrm{CD} 19^{+}$, and $\mathrm{CD}^{+} / \mathrm{CD} 19^{+}$cells were calculated.

\section{Detection of platelet-associated immunoglobulin (PAIgG)}

We added $5 \mu \mathrm{L}$ IgG monoclonal antibody to the measuring tube, and to both the control and measuring tubes, a $50-\mu \mathrm{L}$ platelet suspension was added; both tubes were incubated at room temperature for $15 \mathrm{~min}$. After washing twice with PBS, $20 \mu \mathrm{L}$ FITC-labeled goat anti-mouse IgG was added and incubated at room temperature for $15 \mathrm{~min}$. After washing again with PBS, the sample was analyzed by flow cytometry. For each sample, 5000-10,000 platelets were acquired, and the percentage of fluorescence-labeled positive platelets was determined.

\section{Determination of blood platelet count}

The blood platelet (PLT) count was analyzed before and after treatment (1, 3, and 6 months); $2 \mathrm{~mL}$ whole blood was added to the measuring tube, and EDTA-K2 was added for anticoagulation. The sample was analyzed using the Kurt STKS II automatic blood cell analyzer (Beckman Coulter). All specimens were analyzed within $2 \mathrm{~h}$ of drawing blood. 


\section{PLT standards for evaluating therapeutic effects}

There were 3 grades for evaluating the therapeutic effect of glucocorticosteroid treatment on ITP. 1) Complete response (CR): following treatment with glucocorticosteroids, the PLT count was restored to $\geq 100 \times 10^{9} / \mathrm{L}$, and no symptoms of bleeding were observed. 2) Response (R): after treatment with glucocorticosteroids, the PLT count was restored to $\geq 30 \mathrm{x}$ $10^{9} / \mathrm{L}$, or increased at least 2-fold over the baseline PLT count, with no symptoms of bleeding. 3) Non-response: the PLT count was maintained below $30 \times 10^{9} / \mathrm{L}$ and the increase was less than 2-fold over the baseline PLT count or there were still symptoms of bleeding. When defining the CR or R, the PLT count was tested at least twice with an interval of at least 7 days between tests. Patients in the effective group included patients with $\mathrm{CR}$ and patients with $\mathrm{R}$.

\section{Statistical analysis}

Results were analyzed with the SPSS v11.5 software (Chicago, IL, USA). Measurement data are reported as means \pm standard deviation. Groups were compared using 2 independent samples Student $t$-tests or paired sample $t$-tests. Then, the correlations between the parameters were performed using linear correlation analysis. The level of significance was set at 0.05 .

\section{RESULTS}

\section{Correlative index in patients with ITP and HC}

The percentage of $\mathrm{CD} 19^{+}$and $\mathrm{B} 1$ cells and the PAIgG level in the ITP patients at baseline were significantly higher than those in the control group $(\mathrm{P}<0.05)$, and the PLT count was remarkably lower than that in the control group $(\mathrm{P}<0.05)$ (Table 1$)$.

Table 1. Percentage of $\mathrm{CD} 19^{+}$cells, B1 cells, the PAIgG level, and the blood platelet (PLT) count in healthy control and idiopathic thrombocytopenic purpura (ITP) patients.

\begin{tabular}{lccccc}
\hline Groups & Cases & CD19 $(\%)$ & B1 cells $(\%)$ & PAIgG $(\%)$ & PLT (x10\% $/ \mathrm{L})$ \\
\hline Control & 40 & $11.2 \pm 7.1^{\Delta}$ & $2.2 \pm 1.3^{\Delta}$ & $11.7 \pm 8^{\Delta}$ & $161 \pm 45^{\Delta}$ \\
ITP & 97 & $21 \pm 10.0$ & $8.85 \pm 5.23$ & $28 \pm 19$ & $26 \pm 8$ \\
P value & & $<0.05$ & $<0.05$ & $<0.05$ & $<0.05$ \\
\hline
\end{tabular}

Data are reported as means \pm SD. ${ }^{\Delta} \mathrm{P}<0.05$, compared with the ITP patients at baseline.

\section{Correlative index in patients with ITP in the effective group at 4 time points}

At 1, 3, and 6 months after treatment with glucocorticosteroids, 69 patients with ITP responded to glucocorticosteroids, but 28 cases were still not sensitive to glucocorticosteroid treatment. The percentage of $\mathrm{CD} 19^{+}$and $\mathrm{B} 1$ cells and the PAIgG level in the effective group were reduced remarkably $(\mathrm{P}<0.01)$ compared to those at baseline. The PLT count of the ITP patients in the effective group was enhanced dramatically at 1,3 , and 6 months after the treatment $(\mathrm{P}<0.01$, Table 1) compared to baseline (Table 2$)$. All of these parameters in the effective group were not significantly different from those in the control group $(\mathrm{P}>0.05)$. In contrast, the percentage of $\mathrm{CD}_{1} 9^{+}$and B1 cells, the PAIgG level, and the PLT count in the ineffective group were not different from those at baseline at the 3 time points after treatment 
$(\mathrm{P}>0.05)$; however, they were still significantly different from those of the control group ( $\mathrm{P}$ $<0.05$ ) (Table 3).

Table 2. Percentage of $\mathrm{CD} 19^{+}$cells, B1 cells, the PAIgG level and the blood platelet (PLT) count in the effective group.

\begin{tabular}{lcrrrr}
\hline Groups & Cases & CD19 $(\%)$ & B1 cells $(\%)$ & PAIgG $(\%)$ & PLT $\left(x 10^{9} / \mathrm{L}\right)$ \\
\hline Control & 40 & $11.2 \pm 7.1^{\Delta}$ & $2.2 \pm 1.3^{\Delta}$ & $11.7 \pm 8^{\Delta}$ & $161 \pm 45^{\Delta}$ \\
Baseline & 69 & $20 \pm 9.0^{*}$ & $8.74 \pm 5.04^{*}$ & $25 \pm 17^{*}$ & $25 \pm 3^{*}$ \\
1 month & 69 & $11.05 \pm 4.63$ & $2.45 \pm 1.75$ & $12.56 \pm 7.53$ & $215.91 \pm 64.8$ \\
3 months & 69 & $12.2 \pm 4.75$ & $2.67 \pm 1.82$ & $11.54 \pm 6.83$ & $202.8 \pm 59.7$ \\
6 months & 69 & $12.3 \pm 4.63$ & $2.75 \pm 1.85$ & $13.76 \pm 6.57$ & $197.91 \pm 74.4$ \\
\hline
\end{tabular}

Data are reported as means $\pm \mathrm{SD} . * \mathrm{P}<0.01$ versus the three-time points after treatment; ${ }^{\wedge} \mathrm{P}>0.05$, compared with the three-time points after treatment.

Table 3. Percentage of CD19+ cells, B1 cells, the PAIgG level and the blood platelet (PLT) count in the effective group. count in the ineffective group.

\begin{tabular}{lccccc}
\hline Groups & Cases & CD19 $(\%)$ & B1 cells $(\%)$ & PAIgG $(\%)$ & PLT $\left(\mathrm{x} 10^{9} / \mathrm{L}\right)$ \\
\hline Control & 40 & $11.2 \pm 7.1^{\Delta}$ & $2.2 \pm 1.3^{\Delta}$ & $11.7 \pm 8^{\Delta}$ & $161 \pm 45^{\Delta}$ \\
Baseline & 28 & $21 \pm 10.0^{*}$ & $8.76 \pm 5.26^{*}$ & $28 \pm 19^{*}$ & $26 \pm 8^{*}$ \\
1 month & 28 & $18.7 \pm 10.4$ & $7.9 \pm 5.6$ & $25 \pm 3^{\Delta}$ & $24 \pm 8$ \\
3 months & 28 & $21.1 \pm 9.72$ & $8.19 \pm 4.2$ & $26.1 \pm 5$ & $31 \pm 7$ \\
6 months & 28 & $20.6 \pm 9.8$ & $8.01 \pm 4.4$ & $27 \pm 5$ \\
\hline
\end{tabular}

Data are reported as means $\pm \mathrm{SD} .{ }^{*} \mathrm{P}>0.05$ versus each time point after treatment; ${ }^{\wedge} \mathrm{P}<0.01$, versus each time point after treatment.

\section{Correlation of B1 cells with the PAIgG level and the PLT count in patients with ITP}

Before treatment with glucocorticosteroids, the percentage of B1 cells was negatively correlated with the PLT count $(\mathrm{r}=-0.89, \mathrm{P}<0.05)$ but positively correlated with the PAIgG level $(\mathrm{r}=0.83, \mathrm{P}<0.05)$. Furthermore, the PAIgG level was negatively associated with the PLT count $(\mathrm{r}=-0.814, \mathrm{P}<0.05)$.

\section{Correlation of B1 cells with the prognosis of ITP patients}

According to the percentage of $\mathrm{B} 1$ cells, the 97 patients with ITP could be divided into 3 groups: those with a B1 cell percentage $<4 \%$ ( $N=27$, Group A), and with a PLT count of (32 $\pm 5) \times 10^{9} / \mathrm{L}$; those with a B1 cell percentage between 4 and $8 \%(\mathrm{~N}=41$, Group B), and a PLT count of $(24 \pm 5) \times 10^{9} / \mathrm{L}$; and those with a B1 cell percentage of $>8 \%(\mathrm{~N}=29$, Group C), and a PLT count of $(10 \pm 5) \times 10^{9} / \mathrm{L}$. There were significant differences in the B1 levels between the 3 groups $(\mathrm{P}<0.01)$; however, the response cases in the 3 groups were not different from each other $(\mathrm{P}>0.05)$ (Table 4).

Table 4. B1 levels and response rate of idiopathic thrombocytopenic purpura (ITP) patients in groups A, B, and C.

\begin{tabular}{lccccc}
\hline Groups & Cases & B1 cells (\%) & Response cases (CR+R) & Non-response cases (NR) & Response rate (\%) \\
\hline Group A & 27 & $3.76 \pm 1.21$ & 19 & 8 & 70.37 \\
Group B & 41 & $6.90 \pm 2.50$ & 29 & 12 & 70.73 \\
Group C & 29 & $10.14 \pm 3.1$ & 19 & 10 & 65.51 \\
\hline
\end{tabular}

$\mathrm{CR}=$ complete response; $\mathrm{R}=$ response. 


\section{DISCUSSION}

ITP is a bleeding disorder with an autoimmune destruction of platelets in peripheral blood, which causes the decrease in PLT counts. Currently, its occurrence is believed to be associated with immune function disorders (Emmerich et al., 2007; Godeau, 2013; Kistangari and McCrae, 2013; Mahévas et al., 2013). In recent years, several studies have shown that the level of B1 cells ( $\mathrm{CD}^{+} \mathrm{B}$ lymphocytes) is abnormal in patients with ITP (McMillan et al., 2001; Arita et al., 2003; Donato et al., 2009; Wang et al., 2010; Godeau, 2013; Mahévas et al., 2013), which plays an increasingly important role in the occurrence of ITP. It presents with a significantly increasing percentage of B1 cells and PAIgG, a negative relationship between the percentage of B1 cells and the PLT count and a decreasing percentage of B1 cells after the remission of ITP (McMillan et al., 2001; Arita et al., 2003; Jackson et al., 2008; Shahgholi et al., 2008; Donato et al., 2009; Wang et al., 2010; Mahévas et al., 2013).

This study aimed to further clarify the roles of B1 cells in the pathogenesis of ITP and to evaluate the association of B1 cells with the disease outcome. Our results showed that the percentage of B1 cells and the level of PAIgG were reduced significantly by glucocorticosteroids in the effective group, indicating that the immune state of the ITP patients was restored to a new balance. However, the percentage of B1 cells and the level of PAIgG in the ineffective group were not influenced by glucocorticosteroids, suggesting that the immune state of ITP patients was not sensitive to treatment with glucocorticosteroids and was in a state of imbalance. Our results were consistent with those of previous research (Arita et al., 2003; Emmerich et al., 2007; Salama et al., 2009; Neunert et al., 2011; Kistangari and McCrae, 2013; Mahévas et al., 2013).

We also found that the percentage of peripheral blood B1 cells of the 97 patients with ITP was negatively associated with the peripheral PLT count and positively correlated with the PAIgG level. In addition, the peripheral PLT count was negatively correlated with the PAIgG level. Although the percentage of B1 cells was correlated with the severity of ITP, the response rates of the ITP patients with different levels of B1 cells were not different, which further illustrated that the level of peripheral B1 cells was correlated with the severity of ITP (Shahgholi et al., 2008; Son et al., 2008; Wang et al., 2010). The level of peripheral B1 cells was not associated with the prognosis of ITP. However, its change induced by glucocorticosteroid treatment was correlated with the prognosis of ITP. Thus, if the level of B1 cells in the peripheral blood could be restored to normal levels by treatment with glucocorticosteroids, it can be used as a reference index for the determination of the immune function of patients with ITP. When combined with the PAIgG level and other clinically relevant information, it may provide a basis for establishing individualized treatment for different patients.

In conclusion, this study clarified the important role of cellular immunity in the pathogenesis of ITP and elucidated the value of peripheral blood B1 cells in assessing the therapeutic effect of hormone therapy and its prognostic value for ITP. Our results were consistent with the results from previous studies (Shahgholi et al., 2008; Son et al., 2008; George et al., 2009; Wang et al., 2010), indicating that the detection of peripheral B1 cells is an important reference value for the assessment of the severity and prognosis of ITP. If combined with other indicators, such as PAIgG or platelet membrane glycoprotein, the detection of the peripheral B1 cells can provide a more reliable immunological basis for the individualized treatment for ITP. However, the relationship between the level of B1 cells and the occurrence and treatment of ITP should be further verified by a randomized double-blind study with a larger sample. In this study, PAIgG was used as an indicator for assessing the humoral immunity in ITP. It has 
high sensitivity but relatively poor specificity. If platelet membrane glycoproteins are used, the specificity and reliability for assessing humoral immunity in ITP can be improved (McMillan et al., 2001; Neunert et al., 2008; Shahgholi et al., 2008; Son et al., 2008; George et al., 2009; Wang et al., 2010), but it cannot influence the reliability of the B1 cells used in the assessment of the occurrence and the prognosis of ITP (Salama et al., 2008; Kuter et al., 2009).

\section{ACKNOWLEDGMENTS}

Research supported by the 2012 general project of the Shaoxing Municipal Science and Technology Bureau (\#2012B70067).

\section{REFERENCES}

Arita M, Kodama S, Suzuki M and Mogi G (2003). Single cell analysis of adenoid CD5 ${ }^{+}$B cells and their protective contributions to nasopharyngeal immunity. Laryngoscope 113: 484-491.

Arnold DM, Bernotas A, Nazi I, Stasi R, et al. (2009). Platelet count response to H. pylori treatment in patients with immune thrombocytopenic purpura with and without $H$. pylori infection: a systematic review. Haematologica 94: 850-856.

Bussel JB, Kuter DJ, Pullarkat V, Lyons RM, et al. (2009). Safety and efficacy of long-term treatment with romiplostim in thrombocytopenic patients with chronic ITP. Blood 113: 2161-2171.

Chong BH (2009). Primary immune thrombocytopenia: understanding pathogenesis is the key to better treatments. $J$. Thromb. Haemost. 7: 319-321.

Donato H, Picón A, Martinez M, Rapetti MC, et al. (2009). Demographic data, natural history, and prognostic factors of idiopathic thrombocytopenic purpura in children: a multicentered study from Argentina. Pediatr. Blood Cancer 52: 491-496.

Emmerich F, Bal G, Barakat A, Milz J, et al. (2007). High-level serum B-cell activating factor and promoter polymorphisms in patients with idiopathic thrombocytopenic purpura. Br. J. Haematol. 136: 309-314.

George JN, Mathias SD, Go RS, Guo M, et al. (2009). Improved quality of life for romiplostim-treated patients with chronic immune thrombocytopenic purpura: results from two randomized, placebo-controlled trials. Br. J. Haematol. 144: 409-415.

Godeau B (2013). B-cell depletion in immune thrombocytopenia. Semin. Hematol. 50 (Suppl 1): S75-S82.

Harrington WJ, Minnich V, Hollingsworth JW and Moore CV (1951). Demonstration of a thrombocytopenic factor in the blood of patients with thrombocytopenic purpura. J. Lab. Clin. Med. 38: 1-10.

Jackson SC, Beck P, Buret AG, O’Connor PM, et al. (2008). Long term platelet responses to Helicobacter pylori eradication in Canadian patients with immune thrombocytopenic purpura. Int. J. Hematol. 88: 212-218.

Johnsen J (2012). Pathogenesis in immune thrombocytopenia: new insights. Hematol. Am. Soc. Hematol. Educ. Program. 2012: 306-312.

Kistangari G and McCrae KR (2013). Immune thrombocytopenia. Hematol. Oncol. Clin. North Am. 27: 495-520.

Kuter DJ, Mufti GJ, Bain BJ, Hasserjian RP, et al. (2009). Evaluation of bone marrow reticulin formation in chronic immune thrombocytopenia patients treated with romiplostim. Blood 114: 3748-3756.

Mahévas M, Patin P, Huetz F, Descatoire M, et al. (2013). B cell depletion in immune thrombocytopenia reveals splenic long-lived plasma cells. J. Clin. Invest. 123: 432-442.

Mantadakis E, Farmaki E and Buchanan GR (2010). Thrombocytopenic purpura after measles-mumps-rubella vaccination: a systematic review of the literature and guidance for management. J. Pediatr. 156: 623-628.

McMillan R, Lopez-Dee J and Bowditch R (2001). Clonal restriction of platelet-associated anti-GPIIb/IIIa autoantibodies in patients with chronic ITP. Thromb. Haemost. 85: 821-823.

Mueller BU, Bennett CM, Feldman HA, Bussel JB, et al. (2009). One year follow-up of children and adolescents with chronic immune thrombocytopenic purpura (ITP) treated with rituximab. Pediatr. Blood Cancer 52: 259-262.

Neunert CE, Buchanan GR, Imbach P, Bolton-Maggs PH, et al. (2008). Severe hemorrhage in children with newly diagnosed immune thrombocytopenic purpura. Blood 112: 4003-4008.

Neunert CE, Lim W, Crowther M, Cohen A, et al. (2011). Clinical guideline update on "Immune thrombocytopenia: an evidence based practice guideline developed by the American Society of Hematology". Blood 189: 1182-1196.

Patel VL, Mahevas M, Lee SY, Stasi R, et al. (2012). Outcomes 5 years after response to rituximab therapy in children and adults with immune thrombocytopenia. Blood 119: 5989-5995.

Genetics and Molecular Research 14 (1): 21-28 (2015)

CFUNPEC-RP www.funpecrp.com.br 
Provan D, Stasi R, Newland AC, Blanchette VS, et al. (2010). International consensus report on the investigation and management of primary immune thrombocytopenia. Blood 115: 168-186.

Rodeghiero F, Stasi R, Gernsheimer T, Michel M, et al. (2009). Standardization of terminology, definitions and outcome criteria in immune thrombocytopenic purpura of adults and children: report from an international working group. Blood 113: 2386-2393.

Rostami N, Keshtkar-Jahromi M, Rahnavardi M, Keshtkar-Jahromi M, et al. (2008). Effect of eradication of Helicobacter pylori on platelet recovery in patients with chronic idiopathic thrombocytopenic purpura: a controlled trial. Am. J. Hematol. 83: 376-381.

Ruggeri M, Fortuna S and Rodeghiero F (2008). Heterogeneity of terminology and clinical definitions in adult idiopathic thrombocytopenic purpura: a critical appraisal from a systematic review of the literature. Haematologica 93: 98-103.

Salama A, Kiesewetter H, Kalus U, Movassaghi K, et al. (2008). Massive platelet transfusion is a rapidly effective emergency treatment in patients with refractory autoimmune thrombocytopenia. Thromb. Haemost. 100: 762-765.

Salama A, Rieke M, Kiesewetter H and von Depka M (2009). Experiences with recombinant FVIIa in the emergency treatment of patients with autoimmune thrombocytopenia: a review of the literature. Ann. Hematol. 88: 11-15.

Shahgholi E, Vosough P, Sotoudeh K, Arjomandi K, et al. (2008). Intravenous immune globulin versus intravenous anti-D immune globulin for the treatment of acute immune thrombocytopenic purpura. Indian J. Pediatr. 75: 1231-1235.

Son DW, Jeon IS, Yang SW and Cho SH (2008). A single dose of anti-D immunoglobulin raises platelet count as efficiently as intravenous immunoglobulin in newly diagnosed immune thrombocytopenic purpura in Korean children. $J$. Pediatr. Hematol. Oncol. 30: 598-601.

Spahr JE and Rodgers GM (2008). Treatment of immune-mediated thrombocytopenia purpura with concurrent intravenous immunoglobulin and platelet transfusion: a retrospective review of 40 patients. Am. J. Hematol. 83: 122-125.

Stasi R, Sarpatwari A, Segal JB, Osborn J, et al. (2009). Effects of eradication of Helicobacter pylori infection in patients with immune thrombocytopenic purpura: a systematic review. Blood 113: 1231-1240.

Wang Q, Zhan FX, Hou M, Ding J, et al. (2010). A prospective assessment of the diagnostic value of MAIPA test in idiopathic thrombocytopenic purpura. Zhonghua Xue Ye. Xue Za Zhi 31: 581-585.

Yang L, Wang L, Zhao CH, Zhu XJ, et al. (2010). Contributions of TRAIL-mediated megakaryocyte apoptosis to impaired megakaryocyte and platelet production in immune thrombocytopenia. Blood 116: 4307-4316. 